\title{
Qualidade do leite em sistemas de produção na região Sul do Rio Grande do Sul
}

\author{
Maira Balbinotti Zanela ${ }^{(1)}$, Vivian Fischer ${ }^{(2)}$, Maria Edi Rocha Ribeiro(1), Waldyr Stumpf Junior ${ }^{(1)}$, Claudir Zanela(3), \\ Lúcia Treptow Marques ${ }^{(3)}$ e Paulo Ricardo Garcia Martins ${ }^{(3)}$
}

(1)Embrapa Clima Temperado, BR 392, Km 78, Caixa Postal 403, CEP 96001-970 Pelotas, RS. E-mail: maira@cpact.embrapa.br, dindi@cpact.embrapa.br, stumpf@cpact.embrapa.br (2)Universidade Federal do Rio Grande do Sul, Dep. de Zootecnia, Av. Bento Gonçalves, no 7712, CEP 91540-000 Porto Alegre, RS. E-mail: vfried@portoweb.com.br (3)Universidade Federal de Pelotas, Dep. de Zootecnia, Caixa Postal 354, CEP 96010-900 Pelotas, RS. E-mail: clauzanela@yahoo.com.br, Itmarques@yahoo.com.br, prmartins@hotmail.com

\begin{abstract}
Resumo - O objetivo deste trabalho foi caracterizar a produção e a qualidade do leite em sistemas de produção da região Sul do Rio Grande do Sul e verificar a porcentagem de amostras que se enquadram nos limites determinados pela Instrução Normativa 51 (IN 51). De setembro de 2000 a agosto de 2001, exceto janeiro, foram monitoradas, mensalmente, dez unidades de produção leiteira classificadas nos seguintes sistemas de produção: especializado, semi-especializado e não especializado. Em amostras coletadas no tanque resfriador, foram avaliadas características físico-químicas do leite, realizada a contagem de células somáticas e a produção de leite foi corrigida para $4 \%$ de gordura. Houve diferença significativa entre os sistemas para produção de leite, porcentagens de gordura, lactose, caseína, sólidos totais, sólidos desengordurados, contagem de células somáticas, acidez titulável e densidade. Consideradas todas as características do leite, apenas $41,8 \%$ das amostras se enquadraram nos limites estabelecidos pela IN 51. A maior especialização dos sistemas resultou em aumento da produção de leite e menor contagem de células somáticas, além de maiores valores porcentuais da caseína, lactose e sólidos desengordurados, possivelmente pelo melhor manejo nutricional e higiene na ordenha.
\end{abstract}

Termos para indexação: propriedades físico-químicas do leite, contagem de células somáticas, Instrução Normativa 51, produção de leite.

\section{Milk quality in production systems in the Southern region of Rio Grande do Sul, Brazil}

\begin{abstract}
The objective of this work was to characterize milk yield and quality of production systems in the southern region of Rio Grande do Sul, and verify the proportion of samples in the range allowed by Federal Normative Instruction 51 (IN 51), created to establish quality parameters for milk in the country. From September 2000 to August 2001, except January, ten dairy production units were monthly evaluated and then classified into three productions systems: specialized, partially specialized and nonspecialized. Bulk tank milk was sampled to determine physicochemical characteristics, somatic cell count and milk production was corrected to $4 \%$ milk fat. Production systems differed statistically for milk production, percentages of fat, lactose, casein, total solids, nonfat solids, somatic cell count, acidity and density. Only $41.8 \%$ of samples were in the acceptable range of IN 51 rules. Production systems greatest specialization resulted in higher milk yield, reduced somatic cell count and larger percentages for milk casein, lactose and non-fat solids, probably due to better nutritional management and milking hygiene.
\end{abstract}

Index terms: milk physicochemical properties, somatic cell count, Federal Normative Instruction 51, milk production.

\section{Introdução}

Números relativos à produção de leite no Brasil posicionam o Rio Grande do Sul em terceiro lugar no ranking nacional, com 2,33 bilhões de litros, 1,186 milhões de vacas e produtividade média anual de 1.845 L por animal ordenhado (IBGE, 2002).
A maioria dos produtores brasileiros - cerca de $66,6 \%$ - alcançam até $50 \mathrm{~L}$ de leite por dia, equivalentes a $30,2 \%$ da produção nacional; os $34,4 \%$ restantes produzem acima de $50 \mathrm{~L}$ por dia, representando $69,8 \%$ do total (Bitencourt et al., 2000).

Barros et al. (2001) estipularam as quantidades de 53 L por dia, de 53 a 133 L, e acima de 133 L por dia, de 
modo a caracterizarem, respectivamente, pequenos, médios e grandes produtores de leite no Rio Grande do Sul. Pequenos e médios produtores possuem rebanhos de animais cruzados, e os pequenos empregam a ordenha manual; já grandes e médios produtores possuem rebanhos de raças especializadas Holandês e Jersey e utilizam ordenha mecânica. A região noroeste concentra $54,2 \%$ do leite produzido e, por meio de entrevistas, foi constatado que essa é uma atividade viável e em expansão no Estado.

A abertura dos mercados, resultante da globalização, fez com que os setores produtivos mundiais enfrentassem o grande desafio da competitividade. O setor leiteiro brasileiro apresenta problemas de eficiência produtiva e de qualidade da matéria-prima e, por isso, perde em competitividade (Ribeiro et al., 2000).

Com relação à qualidade do leite, o mercado está se tornando cada vez mais exigente, graças à percepção do papel exercido pelos alimentos e seus componentes sobre a saúde do consumidor. O leite de qualidade deve apresentar composição química (sólidos totais, gordura, proteína, lactose e minerais), microbiológica (contagem total de bactérias), organoléptica (sabor, odor, aparência) e número de células somáticas que atendam os parâmetros exigidos internacionalmente (Ribeiro et al., 2000).

O mercado internacional possui normas rígidas para garantir a qualidade do leite para o beneficiamento industrial. Nos EUA, a regulamentação exige que o leite in natura seja resfriado a $7^{\circ} \mathrm{C}, 2$ horas depois da ordenha, e mantido nessa temperatura ou abaixo. A contagem bacteriana do leite deve ser inferior a $100 \mathrm{mil}$ unidades formadoras de colônias por mililitro, $\mathrm{UFC} \mathrm{mL}^{-1}$; a contagem de células somáticas (CCS) deve ser abaixo de 750 mil células $\mathrm{mL}^{-1}$; e não pode conter resíduos de antibióticos, adulterantes ou água (Philpot \& Nickerson, 2002). Segundo Fonseca \& Santos (2000), a CCS é o instrumento mais preciso de avaliação da saúde da glândula mamária. É considerada normal, para tanque de mistura, a CCS menor ou igual a 300 mil células $\mathrm{mL}^{-1}$; valores superiores a um milhão de células $\mathrm{mL}^{-1}$ representam ocorrências de mastite.

Os países da União Européia baseiam-se no Codex Alimentarius, que indica contagem bacteriana inferior a 100 mil UFC $\mathrm{mL}^{-1}$ e CCS inferior a 400 mil células $\mathrm{mL}^{-1}$. A União Européia possui uma legislação bastante rígida quanto à presença de adulterantes, antibióticos e água (Philpot, 2002). A Nova Zelândia e a Austrália são os maiores exportadores de produtos lácteos. Esses países atendem às exigências de CCS da União Européia. No Canadá, atualmente, a CCS deve ser inferior a 500 mil células $\mathrm{mL}^{-1}$. Entretanto, já está sendo considerada a redução para 400 mil (Philpot \& Nickerson, 2002).

Segundo a Instrução Normativa 51 (IN 51), de 18 de setembro de 2002, do Ministério da Agricultura, Pecuária e Abastecimento (Brasil, 2002), os teores mínimos estabelecidos de gordura, proteína bruta e sólidos desengordurados, para o leite são, respectivamente, 3 , 2,9 e 8,4\%. Na Região Sul, a CCS máxima estabelecida será de um milhão de células $\mathrm{mL}^{-1}$, de julho de 2005 a julho de 2008. O limite será de 750 mil células $\mathrm{mL}^{-1}$, de julho de 2008 a julho de 2011 e, depois desse período, de 400 mil células $\mathrm{mL}^{-1}$.

O número de produtores que ficarão fora dos limites máximos estabelecidos não é muito claro, pois existem poucos dados de caracterização da composição química e da qualidade do leite produzido pelo rebanho gaúcho.

O objetivo deste trabalho foi caracterizar a produção e a qualidade do leite de sistemas de produção utilizados na região sul do Rio Grande do Sul e verificar a porcentagem de amostras que se enquadram nos limites estabelecidos pela IN 51.

\section{Material e Métodos}

Este trabalho foi realizado de setembro de 2000 a agosto de 2001 (exceto janeiro) e corresponde ao segundo ano de monitoramento mensal, de dez unidades de produção leiteira (UPL) da região sul do Rio Grande do Sul. O primeiro ano de monitoramento foi de setembro de 1999 a agosto de 2000 (Gonzalez, 2002); o terceiro ano foi de setembro de 2001 a agosto de 2002 (Martins, 2003), em que algumas UPL monitoradas foram substituídas.

Foram realizadas, ao todo, 110 visitas às UPL, que foram classificadas, depois do período de monitoramento, em sistemas de produção, conforme Gonzalez (2002).

No sistema especializado, foram classificadas quatro UPL, localizadas nos municípios de Pelotas, Santa Vitória e Capão do Leão, das quais três apresentavam animais da raça Holandês e uma apresentava animais da raça Jersey. Quatro UPL ficaram no sistema especializado e estavam localizadas nos municípios de Capão do Leão, Arroio Grande, São Lourenço e Canguçu, das quais duas apresentavam animais da raça Holandês e duas apresentavam animais da raça Jersey. Localizadas nas regiões de Cerrito e Monte Bonito, duas UPL, com predominância de animais da raça Jersey, foram classificadas no sistema não especializado. 
Durante o período de monitoramento, foi realizada uma visita mensal a cada UPL, tendo sido avaliados diversos fatores relacionados ao manejo de ordenha utilizado, estrutura física da propriedade e manejo nutricional do rebanho.

O manejo de ordenha foi avaliado mediante acompanhamento mensal, em que se observaram todos os procedimentos, desde a higiene até o manejo dos animais. O procedimento classificado como adequado neste trabalho foi: sala limpa antes da ordenha dos animais; separação das vacas com mastite clínica ou subclínica crônica para ordenha posterior; condução das vacas de forma calma; desinfecção dos tetos préordenha; secagem dos tetos com toalha de papel descartável e individual; realização do teste de caneca de fundo preto, diariamente, para identificação de mastite clínica; realização do teste de CMT (California Mastitis Test), mensalmente, para detecção de mastite subclínica; imersão das teteiras em solução desinfetante entre a ordenha de um animal e outro; desinfecção dos tetos e alimentação dos animais depois da ordenha.

Com relação à estrutura física das UPL, foi avaliada a existência de sala de ordenha adequada, que permitisse a limpeza do ambiente, assim como equipamento de ordenha e refrigeração.

O manejo nutricional do rebanho foi analisado pela coleta de amostras dos alimentos fornecidos aos animais, assim como pela avaliação visual da disponibilidade de oferta de forragem e da anotação das quantidades fornecidas de silagem, ração ou suplemento. A coleta do suplemento oferecido aos animais foi realizada diretamente no cocho. A silagem foi coletada no silo, tendo a amostra sido retirada de vários pontos. A pastagem foi amostrada por meio da técnica de coleta manual simulando o pastejo, realizada em vários pontos do piquete (Le Du \& Penning, 1982).

Considerando-se os fatores citados, as UPL foram classificadas nos sistemas de produção, conforme Gonzalez (2002): especializado (ES), semi-especializado (SE) e não especializado (NE). No sistema ES, as UPL utilizaram: alimentação à base de ração balanceada, silagem e pastagem cultivada de forma contínua durante o ano, com boa oferta de alimento; sala de ordenha higiênica; sistema de ordenha em circuito fechado; resfriamento com tanque de expansão; curral de espera pavimentado; manejo de ordenha adequado. No sistema SE, as UPL utilizaram: alimentação à base de ração balanceada, silagem e pastagem cultivada, mas não mantiveram a qualidade e a constância durante o ano; sistema de ordenha em circuito fechado ou balde-ao-pé; curral de espera sem piso; manejo de ordenha inconstante. E no sistema NE, as UPL não utilizaram ração balanceada, nem silagem ou pastagem cultivada; apresentaram condições nutricionais e sanitárias precárias; manejo de ordenha inadequado e sistema de ordenha balde-ao-pé ou manual.

Depois da ordenha dos animais, foi coletada amostra de leite composta de forma homogênea, com cerca de $300 \mathrm{~mL}$, do tanque misturador ou dos latões utilizados para armazenamento. Essa amostra foi acondicionada em caixas isotérmicas até a chegada ao Laboratório de Nutrição Animal da Universidade Federal de Pelotas, onde foi mantida sob refrigeração, tendo sido utilizada, posteriormente, para caracterização físico-química do leite de cada UPL. As características físicas avaliadas foram densidade, acidez titulável em graus Dornic e crioscopia (Pereira et al., 2001).

As amostras foram encaminhadas ao Laboratório de Serviço de Análise de Rebanhos Leiteiros, da Universidade de Passo Fundo, para determinação das porcentagens de gordura, proteína bruta, lactose e sólidos totais, por meio de espectrofotometria por radiação infravermelha, no equipamento Bentley 2000 (Fonseca \& Santos, 2000). Além disso, foi realizada a CCS, em contador eletrônico, pela técnica de citometria de fluxo (Somacount 300, da Bentley Instruments, Inc.). Foram realizadas, também, análises de nitrogênio não protéico, porcentagem de caseína e proteína verdadeira, no Laboratório de Nutrição Animal do Dep. de Zootecnia, da Universidade Federal de Pelotas (Pereira et al., 2001).

A produção média de leite foi calculada a partir dos dados de produção do rebanho, divididos pelo número de animais em lactação. A produção foi corrigida para $4 \%$ de gordura (National Research Council, 2001), por meio da fórmula: PLC = 0,4 pl + 15(\% gordura/100)pl, em que PLC é a produção de leite corrigida e pl é a produção de leite.

O delineamento adotado foi o completamente ao acaso, em arranjo fatorial desbalanceado. Os dados foram submetidos à estatística descritiva (médias e desviospadrões), e à análise da variância, considerando-se os efeitos dos sistemas de produção $(n=3)$, meses do ano $(\mathrm{n}=11)$ e propriedades dentro de sistema (sistema ES e $\mathrm{SE}, \mathrm{n}=4$; sistema $\mathrm{NE}, \mathrm{n}=2$ ). A interação sistema $\mathrm{x}$ mês chegou a ser considerada, inicialmente, no modelo; entretanto, como não houve interação significativa em nenhuma das características avaliadas, esse dado foi retirado. Os dados de células somáticas foram 
transformados pela aplicação de logaritmo natural. Foi realizada correlação entre as variáveis. As médias foram comparadas pelo teste DMS de Fischer, utilizando-se o nível de significância 0,05. Nas análises estatísticas, foi utilizado o SAS (SAS Institute, 1989). Este trabalho compreende apenas os resultados referentes ao efeito dos sistemas de produção.

\section{Resultados e Discussão}

Os resultados de probabilidade dos efeitos de sistemas e meses para as características avaliadas encontram-se na Tabela 1. Em relação aos sistemas avaliados, houve diferenças significativas nos teores de gordura, caseína, lactose, sólidos totais e sólidos desengordurados, na produção de leite corrigida para $4 \%$ de gordura e na CCS (Tabela 2). A produção média de leite corrigida para $4 \%$ gordura variou entre os sistemas estudados. Do sistema NE para o SE, e do SE para o ES, observaram-se aumentos, respectivamente, de 82 e $53 \%$ na produção média diária de leite. Esses resultados são semelhantes aos apresentados por Gonzalez (2002), que encontrou médias de 16,38, 9,32 e 5,91 L por vaca por dia, para os sistemas ES, SE e NE, respectivamente.

Segundo Stumpf Junior (2000), a produção de leite representa a resposta da vaca leiteira à alimentação adequada e ao manejo racional dos recursos forrageiros disponíveis, pois a alimentação é o principal fator responsável pela rentabilidade de um sistema de produção de leite. A maior disponibilidade e melhor qualidade dos alimentos, fornecidos no sistema ES (Tabela 3), possibi-

Tabela 1. Probabilidade de rejeição da hipótese de nulidade $(\alpha=0,05)$ dos efeitos de sistemas de produção e meses do ano, sobre as características físico-químicas do leite, produção de leite corrigida para 4\% de gordura (PLC) e contagem de células somáticas (CCS).

\begin{tabular}{lcccr}
\hline Característica & Sistema & Mês & $\mathrm{R}^{2}$ & \multicolumn{1}{c}{$\mathrm{CV}$} \\
\hline Gordura (\%) & 0,0092 & 0,1033 & 0,75 & 11,34 \\
Proteína bruta (\%) & 0,6299 & 0,0838 & 0,80 & 4,50 \\
Proteína verdadeira (\%) & 0,9309 & 0,0002 & 0,61 & 9,42 \\
Caseína (\%) & 0,0019 & 0,0001 & 0,76 & 5,64 \\
Nitrogênio não protéico (\%) & 0,2071 & 0,0001 & 0,60 & 19,28 \\
Lactose (\%) & 0,0001 & 0,0104 & 0,46 & 3,13 \\
Sólidos totais (\%) & 0,0314 & 0,0111 & 0,80 & 4,33 \\
Sólidos desengordurados (\%) & 0,0019 & 0,0056 & 0,75 & 2,70 \\
Acidez titulável ( $\left.{ }^{\circ} \mathrm{D}\right)$ & 0,1349 & 0,0014 & 0,45 & 7,33 \\
Densidade (g L $\left.{ }^{-1}\right)$ & 0,1018 & 0,0013 & 0,48 & 0,11 \\
Crioscopia ( $\mathrm{H}$ ) & 0,0718 & 0,6563 & 0,30 & $-2,77$ \\
PLC (L por vaca por dia) & 0,0001 & 0,0231 & 0,86 & 19,03 \\
CCS (x1.000 células mL ${ }^{-1}$ leite) & 0,0001 & 0,3041 & 0,47 & 5,15 \\
\hline
\end{tabular}

litaram a maior expressão do potencial genético dos animais, além de esse sistema possuir animais mais especializados para produção de leite.

Faria \& Corsi (1986) afirmam que, quando o objetivo do sistema de produção é explorar a performance dos animais - expressa em quilograma de leite por vaca por dia ou quilograma de leite por lactação -, a ênfase do manejo deve ser na melhoria da qualidade do alimento oferecido. Como o objetivo do sistema de produção é alcançar a máxima produtividade de leite por hectare, as práticas de manejo devem proporcionar maior lotação das pastagens.

Martins (2003) concluiu que as UPL apresentam queda na produção quando não dispõem, durante todo o ano, de reservas estratégicas na forma de silagem como alternativa alimentar, e de um adequado fornecimento de concentrado, que venha a suprir as necessidades alimentares do rebanho nos momentos em que a pastagem apresenta problemas quanto à quantidade ou qualidade. Neste estudo, os sistemas ES e SE tinham como componente da dieta dos animais, alimento conservado na forma de silagem.

White et al. (2002) avaliaram o sistema confinado, com uso de dieta total e sistemas a pasto (com suplementação de grão e feno, dependendo da disponibilidade de alimento). O sistema a pasto apresentou menor produção de leite e maior porcentagem de proteína bruta (3,5\%) no leite do que o sistema de confinamento $(3,4 \%)$. Neste trabalho, não foram

Tabela 2. Características químicas e físicas do leite, produção de leite corrigida para 4\% de gordura (PLC) e contagem de células somáticas (CCS), segundo os sistemas de produção: especializado (ES), semi-especializado (SE) e não especializado $(\mathrm{NE})^{(1)}$.

\begin{tabular}{lccc}
\hline Característica & ES & SE & NE \\
\hline Gordura (\%) & $3,60 \mathrm{~b}$ & $3,48 \mathrm{~b}$ & $3,83 \mathrm{a}$ \\
Proteína bruta (\%) & 3,23 & 3,21 & 3,24 \\
Proteína verdadeira (\%) & 3,08 & 3,09 & 3,11 \\
Caseína (\%) & $2,71 \mathrm{a}$ & $2,59 \mathrm{~b}$ & $2,63 \mathrm{~b}$ \\
Nitrogênio não protéico (\%) & 0,034 & 0,035 & 0,032 \\
Lactose (\%) & $4,49 \mathrm{a}$ & $4,39 \mathrm{~b}$ & $4,32 \mathrm{~b}$ \\
Sólidos totais (\%) & $12,18 \mathrm{a}$ & $11,90 \mathrm{~b}$ & $12,21 \mathrm{a}$ \\
Sólidos desengordurados $(\%)$ & $8,57 \mathrm{a}$ & $8,42 \mathrm{~b}$ & $8,38 \mathrm{~b}$ \\
Acidez titulável $\left({ }^{\circ} \mathrm{D}\right)$ & $15,90 \mathrm{a}$ & $15,40 \mathrm{~b}$ & $15,60 \mathrm{ab}$ \\
Densidade $\left.(\mathrm{g} \mathrm{L})^{-1}\right)$ & 1029,10 & 1028,90 & 1028,40 \\
Crioscopia $\left({ }^{\circ} \mathrm{H}\right)$ & $-0,545$ & $-0,542$ & $-0,535$ \\
PLC (L por vaca por dia) & $16,39 \mathrm{a}$ & $10,73 \mathrm{~b}$ & $5,88 \mathrm{c}$ \\
CCS (x1.000 células $\mathrm{mL}^{-1}$ leite) & $247 \mathrm{c}$ & $375 \mathrm{~b}$ & $803 \mathrm{a}$ \\
\hline
\end{tabular}

(1)Médias na mesma linha, seguidas de letras diferentes, apresentam variação significativa pelo teste de Fischer $(\alpha=0,05)$. 
verificadas diferenças em termos de proteína bruta do leite, entre os sistemas estudados. Entretanto, a porcentagem de caseína foi mais elevada no sistema ES (Tabela 2).

Outro fator que pode ter influenciado na diferença de produção de leite, entre os sistemas é a elevação da contagem de células somáticas que está associada à diminuição da produção de leite. O sistema ES apresentou CCS inferior à dos demais (menos de $300 \mathrm{mil}$ células $\mathrm{mL}^{-1}$ ); o sistema $\mathrm{SE}$, valor intermediário; e o NE apresentou a média mais elevada (Tabela 2). Houve uma correlação negativa entre a produção de leite e a contagem de células somáticas ( $\mathrm{r}=-0,37, \mathrm{P}=0,0003, \mathrm{n}=90)$.

A CCS está relacionada a alterações nos componentes do leite, dentre os quais as proteínas apresentam maior variação. A porcentagem de proteína total do leite praticamente não varia; no entanto, há diminuição na porcentagem de caseína e aumento na porcentagem das proteínas do soro. A lactose diminui em cerca de $10 \%$ e ocorre uma diminuição do teor de gordura do leite (Fonseca \& Santos, 2000).

A maior porcentagem de lactose foi encontrada no sistema ES (Tabela 2). A lactose está relacionada à regulação da pressão osmótica na glândula mamária, de forma que maior produção de lactose determina maior produção de leite (Peres, 2001). Houve correlação negativa entre a porcentagem de lactose e a CCS

Tabela 3. Composição bromatológica (\%) dos alimentos fornecidos às vacas em lactação, conforme os sistemas de produção: especializado (ES), semi-especializado (SE) e não especializado (NE).

\begin{tabular}{lrcr}
\hline Variável & ES & SE & NE \\
\hline & \multicolumn{3}{c}{ Pastagem } \\
Matéria seca & 23,37 & 23,63 & 24,28 \\
Proteína bruta & 13,49 & 12,60 & 12,40 \\
Fibra em detergente neutro & 54,73 & 48,07 & 58,86 \\
Fibra em detergente ácido & 32,35 & 32,17 & 31,43 \\
Matéria mineral & 10,34 & 10,26 & 9,53 \\
\hline & \multicolumn{3}{c}{ Concentrado } \\
Matéria seca & 83,98 & 89,97 & 83,12 \\
Proteína bruta & 19,31 & 18,58 & 10,80 \\
Fibra em detergente neutro & 27,65 & 37,06 & 34,35 \\
Fibra em detergente ácido & 7,44 & 10,44 & 10,93 \\
Matéria mineral & 8,65 & 9,28 & 10,13 \\
\hline & \multicolumn{4}{c}{ Silagem } \\
Matéria seca & 28,08 & 23,07 & - \\
Proteína bruta & 8,03 & 7,60 & - \\
Fibra em detergente neutro & 56,58 & 62,96 & - \\
Fibra em detergente ácido & 33,53 & 33,60 & - \\
Matéria mineral & 7,48 & 6,38 & - \\
\hline
\end{tabular}

$(\mathrm{r}=-0,29, \mathrm{P}=0,0026, \mathrm{n}=103)$. A elevada CCS está associada à diminuição na concentração de lactose no leite (Philpot \& Nickerson, 2002). As mudanças no teor de lactose ocorrem por causa da passagem de lactose do leite para o sangue, e da redução da capacidade de síntese de lactose pelo epitélio glandular, em conseqüência das lesões no epitélio (Fonseca \& Santos, 2000).

O teor de sólidos desengordurados foi superior no sistema ES, possivelmente graças à maior porcentagem de lactose e caseína (Tabela 2). Esses resultados diferem dos encontrados por Gonzalez (2002) e Martins (2003), que não identificaram variação significativa nos teores de caseína no leite, entre os sistemas de produção. A porcentagem mais elevada de caseína, no ES, foi possivelmente causada pelo maior aporte de nutrientes, levando-se em conta a dieta disponível nesse sistema, além da menor ocorrência de mastite (que reduz a porcentagem de caseína). O volumoso e o concentrado, fornecidos no sistema ES, apresentaram maiores teores de proteína bruta do que nos demais sistemas.

Logo após sua obtenção, o leite apresenta reação ligeiramente ácida, devido a alguns de seus componentes. Essa acidez, chamada de natural ou aparente, é causada pela albumina $\left(1^{\circ} \mathrm{D}\right)$, pelos citratos $\left(1^{\circ} \mathrm{D}\right)$, pelo dióxido de carbono $\left(1^{\circ} \mathrm{D}\right)$, pelas caseínas $\left(5\right.$ a $\left.6^{\circ} \mathrm{D}\right)$ e pelos fosfatos $\left(5^{\circ} \mathrm{D}\right)$ (Velloso, 1998). A maior porcentagem de caseína, no sistema ES, pode ter determinado a maior acidez titulável do leite.

O teor de sólidos totais foi superior nos sistemas NE e ES, em relação ao SE (Tabela 2). O teor mais elevado de sólidos totais foi influenciado pela maior porcentagem de gordura no sistema NE, em relação aos demais.

A maior porcentagem de gordura, no sistema NE, deve-se às diferenças entre as raças leiteiras dos sistemas, no tocante à produção de leite. O sistema NE possuía duas UPL com predominância de animais da raça Jersey, enquanto o ES apresentava uma com vacas Jersey e três com vacas Holandês. Os porcentuais de gordura e sólidos totais, produzidos pelos animais da raça Jersey, são superiores aos dos animais da raça Holandês (Ribeiro et al., 2000).

A variação na composição do leite entre as duas raças leiteiras utilizadas, encontra-se na Tabela 4.

Com relação à IN 51, apenas 41,8\% das amostras estavam dentro dos limites estabelecidos para composição 
química e CCS do leite (Tabela 5). O sistema ES é o que possui maior porcentagem de amostras que preenchem os requisitos exigidos pela IN 51 (52\%), seguido do NE (41\%) e do SE (32\%) .

Os resultados da CCS demonstram que $94,5 \%$ das amostras estão abaixo do limite máximo estabelecido inicialmente, de um milhão de células $\mathrm{mL}^{-1}$. Se fossem considerados os padrões internacionais dos EUA, de 750 mil células $\mathrm{mL}^{-1}, 87,5 \%$ das amostras estariam abaixo dos limites e, no caso da União Européia, 67\% das amostras apresentaram CCS inferior a $400 \mathrm{mil}$ células $\mathrm{mL}^{-1}$.

Para as características de composição, 28,2\% das amostras não atingiram os teores de gordura mínimos estabelecidos pela IN 51; 15,5\% ficaram abaixo dos teores exigidos de proteína bruta; e 53,6\% apresentam teor inferior ao estipulado para sólidos desengordurados, o que indica que o fator limitante é o teor de sólidos desengordurados. Verifica-se que os sistemas ES e SE, apesar de proverem melhores condições de alimentação, contarem com animais especializados com maior potencial produtivo, apresentam maiores porcentagens de amostras com porcentuais de proteína, gordura e sólidos desengordurados inferiores aos exigidos pela IN 51, em relação ao sistema NE.

O aumento da produção leiteira, nesses sistemas, levou à redução dos porcentuais de alguns componentes químicos do leite. O sistema NE, em comparação com o sistema ES, apresentou maiores porcentuais de amostras com CCS superior ao máximo permitido pela IN 51, em suas três etapas de implantação. Porém,

Tabela 4. Média e desvio-padrão (DP) da composição química, características físicas e produção de leite corrigida (PLC) para 4\% de gordura, do leite, de acordo com a raça dos animais.

\begin{tabular}{|c|c|c|c|c|}
\hline \multirow{2}{*}{ Característica } & \multicolumn{2}{|c|}{ Jersey } & \multicolumn{2}{|c|}{ Holandês } \\
\hline & Média & DP & Média & DP \\
\hline Gordura (\%) & 4,10 & 0,64 & 3,09 & 0,39 \\
\hline Proteína bruta (\%) & 3,42 & 0,26 & 3,02 & 0,15 \\
\hline Proteína verdadeira (\%) & 3,29 & 0,39 & 2,87 & 0,31 \\
\hline Caseína (\%) & 2,77 & 0,29 & 2,52 & 0,20 \\
\hline Nitrogênio não protéico (\%) & 0,034 & 0,01 & 0,034 & 0,01 \\
\hline Lactose $(\%)$ & 4,40 & 0,18 & 4,43 & 0,16 \\
\hline Sólidos totais (\%) & 12,76 & 0,96 & 11,36 & 0,59 \\
\hline Sólidos desengordurados (\%) & 8,66 & 0,41 & 8,27 & 0,30 \\
\hline Acidez titulável ( $\left.{ }^{\circ} \mathrm{D}\right)$ & 16,00 & 1,50 & 15,30 & 1,10 \\
\hline Densidade $\left(\mathrm{g} \mathrm{L}^{-1}\right)$ & 1029,10 & 1,54 & 1028,60 & 1,11 \\
\hline PLC 4\% $\left(\mathrm{L} \mathrm{vaca}^{-1} \mathrm{dia}^{-1}\right)$ & 9,00 & 4,60 & 14,90 & 4,70 \\
\hline
\end{tabular}

verifica-se que a diferença entre os sistemas NE e SE diminuiu, à medida que o valor máximo permitido pela IN 51 também diminuiu de um milhão para 400 mil células $\mathrm{mL}^{-1}$, o que sugere que apenas no sistema ES, os manejos sanitário e de ordenha são conduzidos de forma satisfatória. Os sólidos desengordurados compreendem, basicamente, a proteína bruta, a lactose e a matéria mineral do leite (Fonseca \& Santos, 2000). Como a porcentagem de sólidos desengordurados abaixo dos limites da IN 51, é maior que a da proteína bruta (Tabela 5), é possível que os baixos teores de sólidos e de lactose estejam correlacionados.

Um dos principais problemas enfrentados pelos sistemas de produção de leite da Região Sul do Rio Grande do Sul é a falta de alimentação adequada que acomete os rebanhos leiteiros. Existem sistemas de produção em que as boas condições sanitárias possibilitam um controle adequado da mastite, com a redução da CCS, atingindo os padrões inicialmente estabelecidos pela IN 51; no entanto, apresentam redução na porcentagem de sólidos, em conseqüência das condições de subnutrição. Assim, características regionais deveriam ser consideradas no estabelecimento dos padrões de composição do leite.

Tabela 5. Número de amostras que se enquadram nas características exigidas para qualidade de leite, pela Instrução Normativa 51 do Ministério da Agricultura, Pecuária e Abastecimento, de acordo com os sistemas de produção: especializado (ES), semi-especializado (SE) e não especializado (NE).

\begin{tabular}{lrrrrc}
\hline Característica $^{(1)}$ & ES & SE & NE & Total & \%Total \\
\hline $\mathrm{CCS}>1.000 .000{\text { células } \mathrm{mL}^{-1}}^{-1}$ & 0 & 1 & 5 & 6 & 5,5 \\
$\mathrm{CCS}<1.000 .000{\text { células } \mathrm{mL}^{-1}}^{-1}$ & 44 & 43 & 17 & 104 & 94,5 \\
$\mathrm{CCS}<750.000{\text { células } \mathrm{mL}^{-1}}^{-1}$ & 4 & 18 & 5 & 27 & 24,6 \\
$\mathrm{CCS}<400.00{\text { células } \mathrm{mL}^{-}}$ & 40 & 26 & 12 & 78 & 70,9 \\
Gordura $<3 \%$ & 11 & 19 & 1 & 31 & 28,2 \\
Gordura $\geq 3 \%$ & 33 & 25 & 21 & 79 & 71,8 \\
Proteína $<2,9 \%$ & 6 & 11 & 0 & 17 & 15,5 \\
Proteína $\geq 2,9 \%$ & 38 & 33 & 22 & 93 & 84,5 \\
Sólidos desengordurados $<8,4 \%$ & 21 & 27 & 11 & 59 & 53,6 \\
Sólidos desengordurados $\geq 8,4 \%$ & 23 & 17 & 11 & 51 & 46,4 \\
\hline Amostras não incluídas IN 51 & 21 & 30 & 13 & 64 & 58,2 \\
Amostras incluídas IN 51 & 23 & 14 & 9 & 46 & 41,8 \\
\hline
\end{tabular}

(1)Os valores de CCS $<1.000 .000$ células $\mathrm{mL}^{-1}$ leite, gordura $\geq 3 \%$, proteína $\geq 2,9 \%$ e sólidos desengordurados $\geq 8,4 \%$ correspondem às amostras que se enquadram nos limites estabelecidos pela IN 51, que entrou em vigor nas regiões Sul e Sudeste, em julho de 2005; a partir de 2008, o valor máximo de CCS passará a ser 750.000 células $\mathrm{mL}^{-1}$ de leite; a partir de 2011, o valor máximo de CCS passará a ser 400.000 células $\mathrm{mL}^{-1}$ de leite. 


\section{Conclusão}

1. A maior especialização dos sistemas resulta em maior produção de leite por animal e menor contagem de células somáticas.

2. Os teores de gordura são influenciados pela raça utilizada, e as porcentagens de caseína e sólidos são afetadas, principalmente, pela nutrição do rebanho.

3 . Apenas $41,8 \%$ das amostras de leite se enquadram nos limites estabelecidos pela Instrução Normativa 51.

4. Os padrões de composição química do leite estabelecidos pela IN 51 devem ser revistos, considerando-se as variações regionais.

\section{Referências}

BARROS, G.S.A. de C.; GALAN, V.B.; GUIMARÃES, V. di A.; BACCHI, M.R.P. Sistema agroindustrial do leite no Brasil. Brasília: Embrapa Informação Tecnológica, 2001. 172p.

BITENCOURT, D.; PEGORARO, L.M.C.; GOMES, J.F. Sistemas de pecuária de leite: uma visão na região de Clima Temperado. Pelotas: Embrapa Clima Temperado, 2000. 195p.

BRASIL. Ministério da Agricultura, Pecuária e Abastecimento. Regulamento técnico de identidade e qualidade de leite cru refrigerado. In: BRASIL. Ministério da Agricultura, Pecuária e Abastecimento. Instrução normativa $n^{\circ}$ 51, de 18 de setembro de 2002. Diário Oficial da União, 20 set. 2002. Seção 1, p.13.

FARIA, V.P.; CORSI, M. Índices de produtividade em gado de leite. In: PEIXOTO, A.M.; MOURA, J.C. de; FARIA, V.P. Bovinocultura leiteira: fundamentos da exploração racional. Piracicaba: Fealq, 1986. p.1-16.

FONSECA, L.F.L. da; SANTOS, M.V. dos. Qualidade do leite e controle da mastite. São Paulo: Lemos, 2000. 175p.

GONZALEZ, H.L. Qualidade do leite em diferentes sistemas de produção e meses do ano na bacia leiteira de Pelotas. 2002. 120p. Dissertação (Mestrado) - Universidade Federal de Pelotas, Pelotas.

IBGE. Produção da pecuária municipal. Disponível em: <http:// www.ibge.gov.br>. Acesso em: 2002.
LE DU, Y.L.P.; PENNING, P.D. Animal based techniques for estimating herbage intake. In: LEAVER, J.D. (Ed.). Herbage intake handbook. Maidenhead: Brithish Grassland Society, 1982. p.37-75.

MARTINS, P.R.G. Avaliação da qualidade do leite em diferentes sistemas de produção e meses do ano. 2003. 61p. Dissertação (Mestrado) - Universidade Federal de Pelotas, Pelotas.

NATIONAL RESEARCH COUNCIL. Subcommittee on Dairy Cattle Nutrition. Nutrient requirements of dairy cattle. Washington, DC: National Academy Press, 2001. 381p.

PEREIRA, D.B.C.; SILVA, P.H.F. da; COSTA JUNIOR, L.C.G.; OLIVEIRA, L.L. de. Físico-química do leite e derivados: métodos analíticos. 2.ed. Juiz de Fora: Epamig, 2001. 234p.

PERES, J.R. O leite como ferramenta do monitoramento nutricional. In: FÉLIX, H.D. (Ed.). Uso do leite para monitorar a nutrição e o metabolismo de vacas leiteiras. Porto Alegre: Gráfica da UFRGS, 2001. p.30-45.

PHILPOT, W.N. Qualidade do leite e controle de mastite: passado, presente e futuro. In: CONGRESSO PANAMERICANO DE QUALIDADE DO LEITE E CONTROLE DE MASTITE, 2., 2002, São Paulo. Anais. São Paulo: Instituto Fernando Costa, 2002.

PHILPOT, W.N.; NICKERSON, S.C. Vencendo a luta contra a mastite. São Paulo: Milkbizz, 2002. 192p.

RIBEIRO, M.E.R.; STUMPF JÚNIOR, W.; BUSS, H. Qualidade de leite. In: BITENCOURT, D.; PEGORARO, L.M.C.; GOMES, J.F. Sistemas de pecuária de leite: uma visão na região de Clima Temperado. Pelotas: Embrapa Clima Temperado, 2000. p.175-195.

SAS INSTITUTE (Cary, Estados Unidos). SAS/STAT user's guide: version 6. $4^{\text {th }}$ ed. Cary, NC, 1989.

STUMPF JÚNIOR, W. Produção de leite no Rio Grande do Sul: produtividade e competitividade frente [ao] Mercosul. In: CICLO DE PALES7TRAS EM PRODUÇÃO E MANEJO DE BOVINOS, 5., 2000, Canoas. Ênfase em reprodução e alimentação de bovinos de leite: anais. Canoas: Ed. da Ulbra, 2000. p.19-30.

VELLOSO, C.R.V. Noções básicas da acidez. In: BRITO, J.R.F.; DIAS, J.C. (Ed.). A qualidade do leite. Juiz de Fora: EmbrapaCNPGL; São Paulo: Tortuga, 1998. p.91-98.

WHITE, S.L.; BENSON, G.A.; WASHBURN, S.P.; GREEN JUNIOR, J.T. Milk production and economic measures in confinement or pasture systems using seasonally calved Holstein and Jersey cows. Journal of Dairy Science, v.85, p.95-104, 2002.

Recebido em 15 de outubro de 2004 e aprovado em 9 de maio de 2005 